\title{
RESUMEN
}

La evasión tributaria es una problemática frecuente y conocida en la actualidad. Esto se lleva a cabo mediante actos ilícitos y poco éticos, lo que hace que el Fisco recaude menos ingresos tributarios que los debidos, lo que induce a que se eleve la carga tributaria para los contribuyentes honestos.

El propósito de esta investigación es dar a conocer las medidas implementadas por el Servicio de Impuestos Internos, para el período 2014-2017, con el objeto de disminuir la evasión tributaria nacional.

Esto se llevará a cabo mediante análisis documental, por medio de los Planes de Gestión de Cumplimiento Tributario emitidos por el ente fiscalizador para el período referido, Cuentas Públicas y una carta emitida por la Directora Regional SII de Valparaíso a modo de respuesta, siendo estos codificados a través de las categorías y subcategorías de análisis en el software ATLAS TI.

Finalmente, se han identificado las formas y figuras más frecuentes de evasión, siendo una de ellas la emisión de facturas falsas por parte de los contribuyentes. Las medidas que se mantuvieron en el tiempo para aminorar el incumplimiento tributario, se realizan bajo acciones presenciales y no presenciales. Por otro lado, la efectividad de dichas medidas impuestas por medio de los PGCT, fue evaluada por medio de indicadores de cumplimiento, donde el mayor rendimiento fue por medio de las auditorías tributarias.

Palabras Claves: Evasión tributaria, impuestos, indicadores de cumplimiento.

\section{ANÁLISIS DE LAS MEDIDAS TOMADAS A FAVOR DE LA DISMINUCIÓN DE LA EVASIÓN TRIBUTARIA EN CHILE PARA EL PERÍODO 2014 - 2017}

José Figueroa Álamos ${ }^{1}$ / Cristobal Cisternas Rodríguez² / Erica Cofré Peña ${ }^{3}$

\section{ANALYSIS OF THE MEASURES TAKEN IN FAVOR OF THE DECREASE OF THE EVASION TAXATION IN CHILE FOR THE PERIOD 2014 - 2017}

\section{ABSTRACT}

Tax evasion is a frequent and well-known problem today. This is done through illicit and unethical acts, which causes the Treasury to collect less tax revenue than due, which induces the tax burden to rise for honest taxpayers. The purpose of this investigation is to introduce the measures implemented by the Internal Revenue System (SII), for the 2014-2017 periods, in order to reduce national tax evasion.

This will be done through document analysis, through the Compliance Management Plans Tax issued by the auditing body for the mentioned period, Public Accounts and a letter issued by the Regional Director of Internal Revenue System of Valparaíso as a response, these being codified through the categories and subcategories of analysis in the software ATLAS TI.

Finally, the most frequent forms and figures of evasion have been identified, being one of them the emission of false invoices from taxpayers. The measures that were maintained over time to reduce the tax noncompliance are made under face-to-face and non-face-to-face actions. On the other hand, the effectiveness of these measures imposed through the TAGs, was evaluated through compliance indicators, where the highest performance was through tax audits

Key Words: Tax evasion, taxes, compliance indicators.

${ }^{1}$ Abogado. Magíster en Dirección y Gestión Tributaria. Asesor Tributario. Escuela de Ingeniería Comercial, Universidad de Valparaíso. josemfigueroa.legalcorporativa@gmail.com

2 Licenciado en Sistemas de Información Financiera y Control de Gestión. Universidad de Valparaíso, Facultad Ciencias Económicas y Administrativas, Escuela de Auditoría. cristobal_cisternas@hotmail.com

${ }^{3}$ Licenciada en Sistemas de Información Financiera y Control de Gestión. Universidad de Valparaíso, Facultad Ciencias Económicas y Administrativas, Escuela de Auditoría. erica.cofre.p@gmail.com 
Revista de Investigación Aplicada en Ciencias Empresariales 


\section{PLANTEAMIENTO DEL PROBLEMA}

El cumplimiento tributario en Chile debe ser óptimo e íntegro como parte de la ética y de una buena gestión con la que debieran contar personas naturales y jurídicas chilenas. Sin embargo, en la actualidad se conocen diversos casos de acciones ilícitas y poco éticas cada vez más frecuentes, tentados por el beneficio de no pagar sumas de dinero al Fisco que podrían afectar los recursos disponibles de personas y empresas, lo cual ha llevado a estos últimos a la evasión tributaria. En respuesta a esto, el Servicio de Impuestos Internos ha tomado resguardos para enfrentar esta problemática. La evasión en general, ya sea directa o indirecta, ha provocado numerosas multas y hasta penas de presidio para los responsables de estos delitos que han sido descubiertos.

Barra y Jorratt (1999) hacen referencia sobre la estimación de la evasión tributaria en Chile en junio de ese año, mediante una investigación basada en cálculos de datos publicados por el Banco Central de Chile y el Servicio de Impuestos Internos, el cual señala que la tasa de evasión corresponde a un 19,7\%.

Según el portal de internet Emol (2016), el SIl lanzó un Plan de Gestión de Cumplimiento Tributario, el cual considera variadas técnicas fiscalizadoras que la misma entidad empezará a aplicar desde ese año, para lograr reducir la evasión. Una de estas técnicas, es el incentivo al ahorro y la inversión por medio de depreciación acelerada, franquicias, diferir pago de impuestos, entre otros.

Según Yáñez (2010) "El evasor engaña a las autoridades tributarias declarando menos ingreso o menos ventas que las verdaderamente realizadas, usa facturas falsas, altera su contabilidad, exagera las deducciones, falsea sus exportaciones, etc.".

Según Peña (2017), Michel Jorratt agrega que el arriendo de bienes amoblados es uno de los focos de evasión que más se dispara, sobre todo en temporada de verano.

Dada la creciente alza de la evasión tributaria en Chile y las diferentes formas utilizadas, es necesario el planteamiento de esta problemática para conocer la efectividad de las medidas implementadas por el ente fiscalizador nacional. La modalidad que se utilizará será la de una investigación cualitativa. Se indagarán netamente datos cualitativos que ayudarán a comprender dicha problemática por medio de datos descriptivos basados en investigaciones anteriores.

\section{MARCO TEÓRICO}

En la actualidad, la evasión tributaria se ha presentado en diversos casos de acciones ilícitas y poco éticas a nivel nacional. Se entenderá como tal "el uso de medios ilegales para reducir el pago de impuestos que le correspondería pagar a un contribuyente. El evasor actúa de mala fe, en forma ilícita, incurriendo en dolo para pagar menos impuesto (...) La evasión hace que el Fisco recaude menos ingresos tributarios que los debidos, lo que induce a que se eleve la carga tributaria para los 
contribuyentes honestos. Es, además, un atentado claro y directo a la equidad del sistema tributario y es un deber del Estado combatirla." (Yáñez, 2010; p.1), esto en un período de tiempo determinado, dependiendo de la naturaleza del tributo; ya sea el Impuesto al Valor Agregado o a la Renta.

\section{Evasión}

Se entenderá como el desenlace de huir de una obligación, compromiso 0 dificultad, dependiendo del contexto en el que ocurre. Otra definición señala que "consiste en el incumplimiento doloso de las obligaciones tributarias, generalmente acompañado de maniobras engañosas que buscan impedir que sea detectado el nacimiento 0 el monto de la obligación tributaria incumplida. (Ugalde y García, 2007; p.95).

\section{Elusión}

La elusión tributaria es toda conducta dolosa del contribuyente que tiene como finalidad evitar la configuración del hecho gravado o reducir la base imponible y, consecuencialmente, impedir el nacimiento de la obligación tributaria, valiéndose para ello de fraude de ley, de abuso de derecho o de cualquier otro medio ilícito atípico que no constituya infracción o delito penal, esto según Ugalde y García (2007).

\section{Recaudación Efectiva de Impuestos}

En Chile, la recaudación de impuestos es muy importante, ya que cifras proporcionadas por La Tercera (2014) con referencia a los datos publicados en un informe de OCDE sobre esta materia, señala que esta recaudación total llegó al 19,7\% en 2012 sobre el PIB. Por este motivo a continuación se ilustra en el Gráfico No 1, los datos por año con respecto a la recaudación por tipo de impuesto: IVA, Renta u Otros (Productos Específicos, actos específicos, comercio exterior, varios).

\section{Gráfico N¹: Recaudación por Tipo de Impuestos Serie de Años 2009 - 2016}

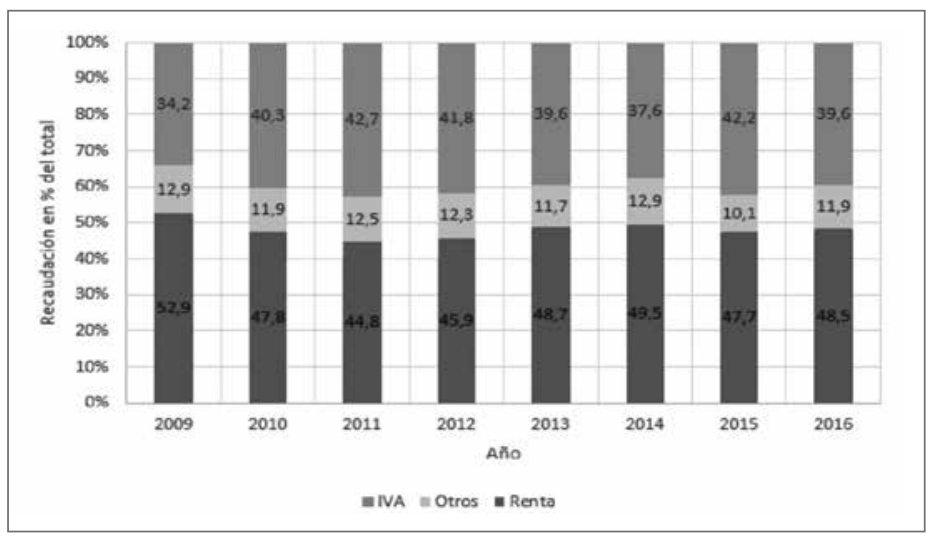

Fuente: Elaboración propia en base a SII (2016-A). 
Como se pudo apreciar en el gráfico $\mathrm{N}^{\circ} 1$ el impuesto más importante de recaudación en Chile es el Impuesto al Valor Agregado (IVA) que grava las ventas y servicios. Por otro lado, le sigue muy de cerca el Impuesto a la Renta quien es el segundo más importante. Por lo tanto, se puede desprender que, según lo mencionado anteriormente, el SII enfoca sus Planes de Gestión de Cumplimiento Tributario en estos dos impuestos que en 2012 llegaron en conjunto a un 89,9\% de la recaudación total del país, convirtiéndose así en las principales fuentes de ingreso Fiscal.

\section{Tasa de Evasión en el IVA}

A continuación, en el gráfico N²2, se aprecian las variaciones que ha presentado la tasa de evasión tributaria impuesta por el SIl desde el año 2006 al año 2016:

\section{Gráfico №2: Tasa de Evasión IVA. Años 2006 a 2016}

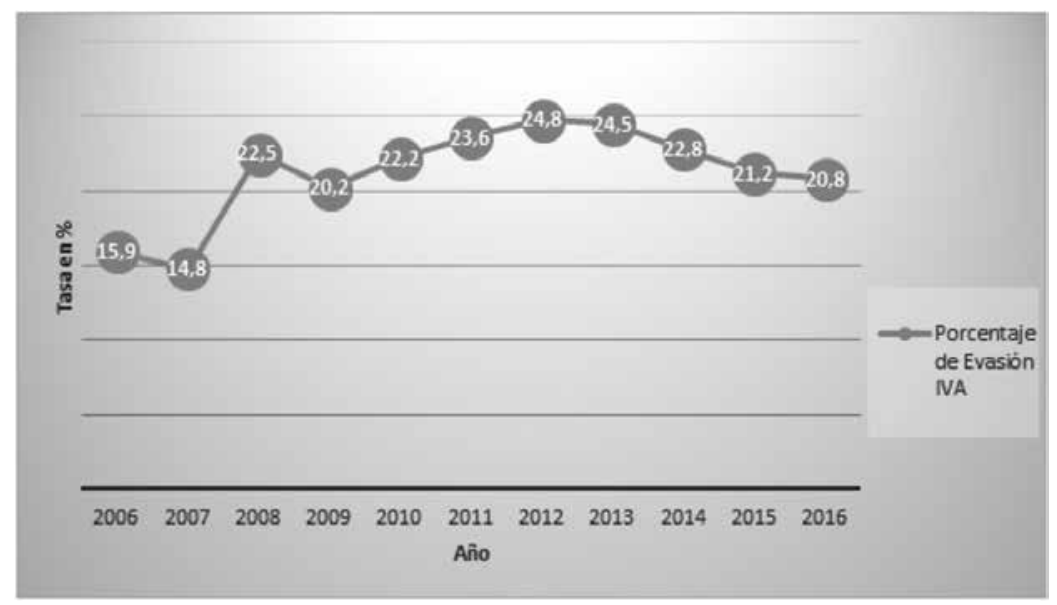

Fuente: Elaboración propia en base a SII (2016-C, 2017-B).

Como se puede apreciar, la baja tasa de evasión del Impuesto al Valor Agregado en 2006 y 2007, se puede explicar por la promulgación de la Ley 19.738 en el gobierno del ex presidente Ricardo Lagos en contra de la evasión, desprendiéndose así la efectividad e importancia que tuvo la misma. Además, se logra dimensionar que desde el año 2012 ha disminuido la tasa de evasión, por lo que la implementación del Plan de Gestión del Cumplimiento Tributario, desde el año 2015, llega para acrecentar aún más la disminución de evasión en los tributos nacionales del Impuesto al Valor Agregado.

\section{Formas y Figuras más frecuentes de Evasión}

Dependiendo de la naturaleza del tributo, existen diversas acciones por parte de los contribuyentes para evadir de alguna forma el Impuesto mensual al Valor Agregado y el Impuesto anual a la Renta. A continuación, se darán a conocer las más frecuentes: 


\section{a) Comercio Informal}

Dentro de las formas y figuras más frecuentes que utilizan los contribuyentes para evadir impuestos, se empezará por definir la evasión dada en el comercio informal por quienes realizan ventas de productos sin previo pago, correspondiente a impuestos mensuales y anuales, como también a las patentes.

\section{b) Facturas Falsas}

Se entenderán como "Documentos frecuentemente empleados para cometer irregularidades tributarias con el fin de evadir impuestos. Por esta razón, no solamente se castigan ciertas conductas en las cuales estas se utilizan como medio de comisión de un delito, sino también su confección, venta o facilitación, para cometer o posibilitar la comisión de delitos tributarios." (Mora, D. y Mora, H; 2007, p.36).

\section{c) Arriendo de Bienes Inmuebles}

La ley señala, de manera expresa, que el dueño de un bien raíz amoblado en arriendo deberá considerar el pago del Impuesto al Valor Agregado (IVA) e Impuesto a la Renta, por los ingresos que este le genere a su propietario. El ex director del SII, Jorratt (2017), señala "Me atrevo a afirmar que debe haber una alta evasión en arriendos de casas de veraneo. La gente que tiene una segunda vivienda y la arrienda en el verano, normalmente desconoce que debe pagar, por ejemplo, el IVA". (Peña, 2017; p.1). Por otro lado, el SIl reconoce que de igual forma existen contribuyentes con conocimiento de causa de las leyes que deben cumplir, por lo que evaden impuestos de manera directa.

\section{Medidas para Disminuir la Evasión}

El Servicio de Impuestos Internos mediante la publicación de su Plan de Gestión del Cumplimiento Tributario (PGCT) pone a disposición de la comunidad de forma anual las medidas y acciones a utilizar para incentivar y controlar el cumplimiento de obligaciones tributarias, para así reducir las brechas y los riesgos de incumplimiento por parte de los contribuyentes, y con esto finalmente disminuir la tasa de evasión.

\section{A) Medidas orientadas al Impuesto al Valor Agregado}

El SIl cuenta con las siguientes medidas y procedimientos a utilizar para reducir la tasa de evasión por año:

\section{Comercio Informal}

El SIl (2016-F) introdujo cambios en el proceso de control de carreteras, de manera que esta modalidad de fiscalización se oriente a sectores e industrias con mayor propensión a operar en la informalidad.

Asimismo, el SIl (2017-C) señala que el control sobre las bodegas destinadas al comercio se hará efectivo, puesto que estas pudiesen ser ocupadas con fines relacionados al comercio informal. 


\section{Cambios de sujeto}

Teniendo presente la modificación que hizo la ley 20.780 al artículo 3 de la Ley del IVA: el SII (2015-A) en su plan consideró la incorporación de segmentos que presentan altos niveles de incumplimiento tributario al enfoque de cambio de sujeto, el que por regla general supone que es el propio comprador quien debe enterar el IVA de la operación.

Asimismo, haciendo uso del Art. $3^{\circ}$ de la Ley sobre Impuesto a las Ventas y Servicios, el SII (2016-F) estudió la aplicación de cambio de sujeto para contribuyentes que presentan importantes brechas en el sector minero y a ciertos proveedores de servicios a empresas estatales. El SII (2017C), contempla analizar y fiscalizar a los contribuyentes que registran brechas relevantes por concepto de ingresos por Contratos de Instalación o Confección de Especialidades en la Construcción.

\section{Control sobre las Compras en Supermercado y Comercios Similares}

El SII (2015-A) estuvo analizando y caracterizando mediante actividades no presenciales a los contribuyentes de primera categoría que realizan grandes 0 frecuentes compras en supermercados y comercios similares, y que los registren equivocadamente como créditos.

En este contexto, a contar del mes de marzo de 2016, el SII (2016-F) se desplegó mensajes electrónicos a diferentes contribuyentes para informarles que, de acuerdo con las bases de datos, registran compras de esa naturaleza y que, a contar del segundo semestre, se inician fiscalizaciones a quienes excedan los márgenes permitidos 0 cuyas compras no guarden relación con el giro del negocio.

\section{Exportadores}

En este ámbito el SIl (2015-A), principalmente, procedió a verificar el cumplimiento tributario de contribuyentes autorizados a solicitar devolución anticipada del IVA, esto ya sea para futuros proyectos de exportación y de exportadores habituales sin solicitud de devolución.

El SII (2016-F), propuso las acciones a emplear mediante los dos servicios y siendo complementarias entre sí es revisar la actitud hacia el cumplimiento del contribuyente en la selección de casos a revisar y su respectivo alcance. En segundo lugar, la caracterización y el análisis de contribuyentes exportadores de servicio. Y por último la aplicación de acciones de tratamiento a contribuyentes que operan desde la informalidad. 
El principal foco, según el SIl (2017-C) está en los créditos fiscales de los contribuyentes que, de acuerdo con determinados parámetros, posean riesgos específicos relevantes como excesivos volúmenes de compra en relación a las ventas realizadas, compras efectuadas a empresas relacionadas, sin que se produzca la entrega real o simbólica de los bienes respectivos, proveedores que frecuentemente incumplen con los débitos fiscales respectivos o que evidencian la falta de activos.

\section{Control sobre Documentos Tributarios}

\section{- Control IVA Aleatorio}

EI SII (2015-A), realizó el método de control IVA aleatorio. En cuyo proceso, se seleccionan aleatoriamente casos para ser revisados en profundidad y de acuerdo a las facultades fiscalizadoras contenidas en la Ley 18.320.

En 2016, cerca de 28 mil contribuyentes recibieron cartas de aviso, 0 notificaciones electrónicas, mediante las cuales el SII (2016-F) les informó que durante el segundo semestre de ese año serían fiscalizados por regla general en terreno, con el propósito de evaluar su comportamiento tributario en términos de emisión de documentos principalmente.

\section{- Control sobre la emisión de Documentos Tributarios Electrónicos}

En 2014, el SII (2015-A) inició un modelo de control sobre la oportunidad y calidad de los Informes Electrónicos de Compra y Venta (IECV) que deben informar mensualmente los contribuyentes facturadores electrónicos.

Complementariamente a lo anterior, el SIl (2016-F) estuvo implementando modernas herramientas tecnológicas para fortalecer su plataforma informática analítica, principalmente aquella relacionada a información sobre facturas electrónicas.

\section{B) Medidas orientadas al Impuesto a la Renta}

Con respecto al Impuesto a la Renta, a continuación, se pueden visualizar las siguientes medidas y procedimientos a utilizar para los periodos ya definidos:

\section{Control de Boletas de Honorarios y Facturas Exentas}

"Al igual que en períodos anteriores, se controlarán las transacciones de personas y empresas que declaren boletas de honorarios a empresas dirigidas 0 controladas por personas relacionadas." (SII, 2015-A; p.12) 
EI SIl (2016-F) ha puesto a disposición, en la plataforma de la Operación Renta, la información de boletas y facturas emitidas 0 recibidas desde empresas o personas que se consideren relacionadas, de modo tal que el interesado pueda verificar si tales documentos cumplen los requisitos legales.

\section{Rentas originadas de Instrumentos Financieros}

El año 2015 se comenzó a controlar la no declaración o sub declaración de rentas por personas naturales que efectuaron operaciones con instrumentos derivados $\mathrm{y} / 0$ contratos por diferencia, lo que permitió evidenciar altos niveles de incumplimiento tributario. (SII, 2015-A). Durante este año 2016, se continuó reforzando la caracterización de estos instrumentos financieros y, especialmente, el rol y las responsabilidades que le caben a los agentes financieros. (SII, 2016-F).

Durante el año 2017, se reforzará la caracterización de estos instrumentos financieros, para lo cual se pondrá en consulta una encuesta a los contribuyentes que utilizan habitualmente este tipo de instrumentos. (SII. 2017-C).

\section{Rentas de Fuente Extranjera}

El SII (2015-A) puso en énfasis las medidas orientadas a controlar los siguientes grupos de contribuyentes o figuras como: la omisión de rentas de fuente extranjera obtenidas por parte de contribuyentes con domicilio 0 residencia en Chile. Además, estuvo negociando diferentes convenios para el intercambio de información, los que permiten reforzar este ámbito.

\section{Declaraciones Juradas y Formulario 22}

Se intensificaron las acciones preventivas para la presentación de Declaraciones Juradas y Formulario 22 de Impuestos Anuales a la Renta, como, por ejemplo: Disposición de acciones preventivas para informar a los contribuyentes los errores comunes que usualmente afectan sus declaraciones y a terceros con el objetivo que le den solución. SII (2016F). Se continúa con verdadero énfasis la revisión de contribuyentes de primera categoría que no han declarado su F22. Para el anterior caso, el análisis comprenderá la definición de atributos de riesgo, valorización, identificación de causas y estrategias de fiscalización. SII (2017-C)

\section{C) Medidas de carácter mixto (Bienes Raíces)}

Con respecto al plan impulsado en 2017, el SII (2017-C) se enfoca en los siguientes puntos: 
- En cuanto a la explotación de bienes raíces, el énfasis estará en la aplicación de acciones correctivas, asociadas al rubro de arrendamiento de bienes inmuebles amoblados, los cuales se encuentran afectos a IVA.

- Verificar la correcta tributación en el Impuesto a la Renta sobre el cedente de promesas de compra-venta de inmuebles.

- $\quad$ En formato de piloto y haciendo uso de técnicas de georreferenciación se desplegarán revisiones de riesgo para establecer si se está dando correcto cumplimiento tributario.

- Mediante la información otorgada por las entidades financieras como los bancos, se revisarán inversiones en bienes raíces de contribuyentes. que no denotan ingresos o declaran valores desproporcionados de tales bienes.

\section{Actividades preventivas y correctivas en general}

Complementariamente a las medidas específicas tomadas por el SIl que han sido anteriormente descritas, este organismo llevó a cabo tanto acciones presenciales como no presenciales.

Las acciones presenciales del SIl (2015-A, 2016-F, 2017-C) son las siguientes:

- Verificación de cumplimiento tributario en terreno.

- $\quad$ Revisiones presenciales de riesgo.

- Revisiones de cumplimiento.

- Auditorías.

Por otro lado, las acciones no presenciales del SIl (2015-A, 2016-F, 2017-

C) son las siguientes:

- Avisos electrónicos.

- Controles remotos de declaraciones de IVA o Renta.

- Mensajes emergentes.

- Evaluaciones de riesgo no presencial.

\section{Efectividad de los Planes}

En relación a las medidas que se describen en los planes y que fueron mencionados anteriormente, y la efectividad estimada que es publicada en la Cuenta Pública del SII, se pudo obtener la tabla №1: 


\section{Tabla №1: Rendimiento estimado en \$MM en relación al Plan de Gestión del Cumplimiento Tributario. Años 2013 - 2016.}

\begin{tabular}{|l|l|l|l|l|}
\hline Año & Medidas IVA & Medidas Renta & Auditorías & Total Plan \\
\hline 2013 & 158 & 338 & 778 & 1.274 \\
\hline 2014 & 180 & 216 & 800 & 1.196 \\
\hline 2015 & 192 & 290 & 1.200 & 1.682 \\
\hline 2016 & 160,98 & 369,086 & 1.150 & $1.680,066$ \\
\hline
\end{tabular}

Fuente: Elaboración propia en base a datos del SII. (2014, 2015-B, 2016-D, 2017-B).

Sobre la efectividad del Plan de Gestión y la publicación del rendimiento estimado sobre estos expresados en la tabla $N^{\circ} 1$, se puede concluir que la actividad de realizar auditorías (acción presencial) es que más rendimiento estimado genera por sobre las otras dos medidas (IVA y Renta), ya que obtiene más del $60 \%$ en cada año. Además, agregar que para los años 2015 y 2016, se obtuvieron los más altos rendimientos estimados ( $\$ 1.682$ y $\$ 1.680,066$, respectivamente, expresados en MM), por lo que se puede concluir que el SIl se esfuerza cada año en aumentar (en cantidad y efectividad) las medidas y acciones para aumentar dicho rendimiento estimado.

\section{PROPUESTA METODOLÓGICA}

La investigación se focalizó en la metodología cualitativa con un alcance de comprehensión, obteniendo los antecedentes necesarios con el fin de analizar las medidas tomadas por parte del Servicio de Impuestos Internos a favor de la disminución de la evasión tributaria en Chile, desde el punto de vista de la comprensión del fundamento de esta, identificando las medidas más utilizadas y que se han mantenido en el tiempo, explicando también su efectividad. Todo esto a través de análisis documental mediante PGCT, Cuentas Públicas y carta de respuesta de la Dirección Regional del SIl de la Región de Valparaíso. 


\section{ANÁLISIS DE RESULTADOS}

A continuación, se presenta el respectivo análisis de resultados obtenido del análisis documental efectuado, datos tabulados de acuerdo a las categorías y subcategorías de análisis establecidas.

\begin{tabular}{|c|c|c|}
\hline Categoría & Sub Categoría & Conclusiones \\
\hline \multirow{4}{*}{$\begin{array}{l}\text { Formas y } \\
\text { Figuras más } \\
\text { Frecuentes } \\
\text { de Evasión }\end{array}$} & $\begin{array}{l}\text { Arriendo de } \\
\text { Bienes Inmuebles }\end{array}$ & $\begin{array}{l}\text { Según el PGCT, esta figura de evasión tributaria se fundamenta, } \\
\text { principalmente, por el desconocimiento de las personas que } \\
\text { arriendan bienes raíces amoblados de manera habitual o } \\
\text { esporádica, en cuanto a sus obligaciones tributarias con respecto } \\
\text { a la declaración de IVA en relación a este rubro. }\end{array}$ \\
\hline & Facturas Falsas & $\begin{array}{l}\text { Según la Directora Regional del SII de la región de Valparaíso Teresa } \\
\text { Conejeros, mediante carta, actualmente, la forma más utilizada } \\
\text { por los contribuyentes para evadir impuestos es la tendencia a } \\
\text { aumentar el monto de los créditos con los que efectivamente se } \\
\text { cuenta. Esto se lleva a cabo mediante facturas ideológicamente } \\
\text { falsas y la alteración de datos a la hora de declarar y pagar el } \\
\text { Formulario } 29 \text {. }\end{array}$ \\
\hline & $\begin{array}{l}\text { Incumplimiento en } \\
\text { la Presentación de } \\
\text { Formularios }\end{array}$ & $\begin{array}{l}\text { Según el PGCT y la Cuenta Pública, esta forma es una de las } \\
\text { más utilizadas por los contribuyentes, viéndose reflejada en el } \\
\text { Formulario N²2 y 29. Para el año 2016, el foco de brechas se } \\
\text { centró en los Formularios anteriormente mencionados, y también } \\
\text { en Inactivos y Declaraciones Juradas. En el año } 2017 \text {, aún con } \\
\text { los esfuerzos del año anterior, la Declaración de Impuesto a la } \\
\text { Renta no se declaró en un } 23,2 \% \text { de los casos. La Declaración de } \\
\text { Impuestos Mensuales, donde se hace pago de IVA, no se declara } \\
\text { en un } 17,5 \% \text {. Incluso, más grave es la situación del Formulario } \\
\text { No1884 asociado a Dividendos, que alcanza un } 72 \% \text { de evasión } \\
\text { en la presentación del mismo. }\end{array}$ \\
\hline & Comercio Informal & $\begin{array}{l}\text { Durante el año 2016, el PGCT indica que la Región Metropolitana } \\
\text { del país se compone de una cantidad importante de bodegas y } \\
\text { almacenes que abastecen diversas industrias, las cuales operan } \\
\text { sin cumplir sus obligaciones tributarias a la hora de transar } \\
\text { operatorias de compra y venta con importadores y fabricantes, } \\
\text { dentro de los cuales algunos no emiten facturas. }\end{array}$ \\
\hline \multirow[t]{2}{*}{$\begin{array}{l}\text { Énfasis en } \\
\text { las Medidas } \\
\text { Adoptadas } \\
\text { por el SIl }\end{array}$} & $\begin{array}{l}\text { Impuesto al Valor } \\
\text { Agregado }\end{array}$ & $\begin{array}{l}\text { Para el año } 2015 \text {, el PGCT señala que los esfuerzos para combatir } \\
\text { la evasión tributaria nacional se centran, principalmente en } \\
\text { acciones que buscan la correcta declaración de IVA, dado a que } \\
\text { este impuesto representa el } 50 \% \text { de los ingresos tributarios del } \\
\text { país. Actualmente, el Formulario } 29 \text { de Declaración de Impuestos } \\
\text { Mensuales no se presenta en un } 17,5 \% \text { de los casos, por lo tanto, } \\
\text { este indicador debe ser monitoreado de manera constante. El fin } \\
\text { de estas acciones permite aminorar los altos niveles estimados de } \\
\text { evasión en los últimos años. }\end{array}$ \\
\hline & Enfoque Mixto & $\begin{array}{l}\text { La Cuenta Pública indica que en el año } 2016 \text {, los esfuerzos se } \\
\text { enfocaron en las medidas con respecto a ambos tipos tributos } \\
\text { (IVA y Renta), adicional a esto se considera también para este } \\
\text { período la factura electrónica e IVA al exportador. }\end{array}$ \\
\hline
\end{tabular}




\begin{tabular}{|c|c|c|c|}
\hline Categoría & Sub Categoría & Sub - Sub Categoría & Conclusiones \\
\hline \multirow{5}{*}{$\begin{array}{l}\text { Medidas } \\
\text { más } \\
\text { Frecuentes } \\
\text { Acogidas }\end{array}$} & \multirow{5}{*}{ Orientadas al IVA } & $\begin{array}{l}\text { Comercio No } \\
\text { Formalizado }\end{array}$ & $\begin{array}{l}\text { A modo de fiscalización exhaustiva, } \\
\text { el SIl incurrirá en acciones en terreno, } \\
\text { geo-referenciación, empadronamiento } \\
\text { y captura de información, con el fin de } \\
\text { conocer el verdadero uso que se les da a } \\
\text { las bodegas destinadas al comercio, que } \\
\text { operan de manera informal, todo esto } \\
\text { según el PGCT. }\end{array}$ \\
\hline & & Cambios de Sujeto & $\begin{array}{l}\text { Se desprende del PGCT que se } \\
\text { han implementado procedimientos } \\
\text { administrativos, como también } \\
\text { una aplicación informática, la cual } \\
\text { recibe, procesa y entrega en detalle } \\
\text { las devoluciones por este concepto, } \\
\text { tomando como base fuentes de } \\
\text { información y riesgo asociado a cada } \\
\text { caso. Además, serán fiscalizados, } \\
\text { principalmente, agentes retenedores que } \\
\text { facturen de manera electrónica. }\end{array}$ \\
\hline & & Exportadores & $\begin{array}{l}\text { En cuanto a las solicitudes de devolución } \\
\text { por concepto de IVA Exportadores, el } \\
\text { PGCT señala que se reforzarán auditorías } \\
\text { posteriores a las devoluciones que se } \\
\text { efectúen a los contribuyentes. Además, } \\
\text { se han implementado herramientas de } \\
\text { auditoría informática, con el servirán de } \\
\text { apoyo para el proceso de auditoría. Estas } \\
\text { actividades se coordinan en conjunto } \\
\text { con el Servicio Nacional de Aduanas. }\end{array}$ \\
\hline & & $\begin{array}{l}\text { Control sobre } \\
\text { Documentos } \\
\text { Tributarios }\end{array}$ & $\begin{array}{l}\text { El Servicio, según el PGCT, está llevando } \\
\text { a la práctica modernas herramientas } \\
\text { tecnológicas, esto para fortalecer la } \\
\text { fiscalización de documentos tributarios, } \\
\text { en especial de las facturas electrónicas. } \\
\text { Se tendrá especial cuidado con los } \\
\text { nuevos contribuyentes y con los que no } \\
\text { han sido controlados en los últimos tres } \\
\text { años. }\end{array}$ \\
\hline & & $\begin{array}{l}\text { Control sobre } \\
\text { Compras en } \\
\text { Supermercados y } \\
\text { Comercios Similares }\end{array}$ & $\begin{array}{l}\text { Las acciones del SIl estarán enfocadas } \\
\text { a las compras en supermercados y } \\
\text { similares que se realicen de manera } \\
\text { frecuente por parte de un contribuyente, } \\
0 \text { que estas sean de un gran volumen. } \\
\text { Por otro lado, existen actividades no } \\
\text { presenciales, en las cuales se les } \\
\text { advertirá a los contribuyentes en caso de } \\
\text { que, en años anteriores, hayan realizado } \\
\text { compras con esas características, esto } \\
\text { de acuerdo al PGCT. }\end{array}$ \\
\hline
\end{tabular}




\begin{tabular}{|c|c|c|c|}
\hline Categoría & Sub Categoría & Sub - Sub Categoría & Conclusiones \\
\hline & \multirow{5}{*}{$\begin{array}{l}\text { Orientadas a la } \\
\text { Renta }\end{array}$} & $\begin{array}{l}\text { Control de Boletas de } \\
\text { Honorario }\end{array}$ & $\begin{array}{l}\text { En este caso, mediante actividades no } \\
\text { presenciales, se utilizará un enfoque } \\
\text { escalonado, de cruces de información y } \\
\text { el grado de relación que existe entre las } \\
\text { partes. Con respecto a las actividades no } \\
\text { presenciales, éstas serán principalmente } \\
\text { mediante avisos y correos electrónicos, } \\
\text { según el PGCT. }\end{array}$ \\
\hline & & $\begin{array}{l}\text { Rentas de Fuente } \\
\text { Extranjera }\end{array}$ & $\begin{array}{l}\text { EI PGCT indica que lo principal se } \\
\text { encuentra en exigir el cumplimiento } \\
\text { de presentar declaraciones juradas } \\
\text { por inversiones que se efectúan en el } \\
\text { extranjero, debido a la omisión de las } \\
\text { rentas de fuente extranjera que reciben } \\
\text { los contribuyentes domiciliados o } \\
\text { residentes en Chile. Además, medidas } \\
\text { contra las cuentas bancarias en el } \\
\text { extranjero, que no sean declaradas. }\end{array}$ \\
\hline & & $\begin{array}{l}\text { Rentas Originadas } \\
\text { de Instrumentos } \\
\text { Financieros }\end{array}$ & $\begin{array}{l}\text { Se controlan los contribuyentes en } \\
\text { base a que realicen la declaración de } \\
\text { rentas que afectan al impuesto Global } \\
\text { Complementario, así mismo, a aquellos } \\
\text { que no estén formalmente regulados } \\
\text { por la SVS. Para las empresas que se } \\
\text { dedican a intermediar los instrumentos } \\
\text { financieros se comienzan a realizar } \\
\text { fiscalizaciones debido al precario nivel } \\
\text { de cumplimiento tributario, según el } \\
\text { PGCT. }\end{array}$ \\
\hline & & Plan Integral FUT & $\begin{array}{l}\text { Como una medida específica se tiene a } \\
\text { un plan piloto con respecto al ISFUT para } \\
\text { los contribuyentes con alto riesgo global. } \\
\text { También se controlarán los retiros } \\
\text { en exceso generados hasta } 31-12- \\
2014 \text {, existentes al } 31-12-2016 \text { q que } \\
\text { fueron suprimidas de las declaraciones } \\
\text { anormalmente, como refleja el PGCT. }\end{array}$ \\
\hline & & $\begin{array}{l}\text { Declaraciones Juradas } \\
\text { y Formulario } 22\end{array}$ & $\begin{array}{l}\text { Mediante el PGCT, se toman en cuenta } \\
\text { acciones preventivas con el objeto de } \\
\text { que los contribuyentes no cometan } \\
\text { errores usuales que afecten sus } \\
\text { declaraciones, esto se logrará gracias a } \\
\text { informaciones y formularios adaptables } \\
\text { para que no se cometan errores con } \\
\text { respectos a los códigos a utilizar. }\end{array}$ \\
\hline & Orientación Mixta & Bienes Raíces & $\begin{array}{l}\text { El SII, en conjunto con las Direcciones } \\
\text { Regionales, ha creado un Plan Integral } \\
\text { de Tratamiento para Brechas y Riegos } \\
\text { en su PGCT, en cuanto a bienes raíces, } \\
\text { tomando en cuenta objetivos específicos } \\
\text { y realidades territoriales, de acuerdo a } \\
\text { cada región. }\end{array}$ \\
\hline
\end{tabular}




\begin{tabular}{|c|c|}
\hline Categoría & Conclusiones \\
\hline $\begin{array}{l}\text { Efectividad } \\
\text { de las } \\
\text { Medidas } \\
\text { Adoptadas }\end{array}$ & $\begin{array}{l}\text { Gracias a la ley N²0.780 sobre la Reforma Tributaria y a las acciones estructurales, } \\
\text { preventivas y correctivas adoptadas por el SII (según la Directora Regional de la región } \\
\text { de Valparaíso Teresa Conejeros), se obtuvo un incremento del } 17 \% \text { en la recaudación } \\
\text { de impuestos del año } 2014 \text { (Cuenta Pública), esto tras el combate contra la evasión. } \\
\text { Para el año 2015, la Cuenta Pública informó que esta cifra aumentó a un } 33,8 \% \text { más } \\
\text { de lo esperado para ese período, lo que infiere la efectividad de las medidas. Por } \\
\text { otro lado, el PGCT señala que, tras las medidas implementadas por el SIl a partir } \\
\text { del año 2014, un } 70 \% \text { de los contribuyentes cumple con el pago de tributos en los } \\
\text { plazos establecidos por ley. Desde el otro extremo, solo un } 2 \% \text { de los contribuyentes } \\
\text { no cumple, por lo que se evidencia una baja probabilidad de evasión, gracias a las } \\
\text { medidas impuestas a favor. }\end{array}$ \\
\hline
\end{tabular}

\section{DISCUSIÓN DE RESULTADOS}

Con respecto a la investigación realizada, las formas y figuras más frecuentes de evasión se ven reflejadas, principalmente, por medio de la omisión de emisión de documentos tributarios, lo cual conllevan a la obligación tributaria, que, al no ser cumplida, puede verse en beneficio de la entidad en el no pago de impuestos, y también, al ser superior el crédito con respecto al débito con el que cuenta una entidad, se genera un activo para la empresa, el cual podrá ser usado en períodos futuros. Por otro lado, esto se relaciona con el posible desconocimiento de la normativa por parte de los contribuyentes, por lo que se podría decir que una cosa lleva a la otra. Otra de las causas por las que se produce un aumento en la evasión, es la falta de fiscalización por el SII, esto a pesar de que gracias a la ley № 20.780 sobre la Reforma Tributaria impuesta por la presidenta Michelle Bachelet, la cual ha significado un aumento en la dotación del personal, según la Cuenta Pública, el servicio no puede abarcar por cada una de las situaciones anteriormente descritas. Un ejemplo claro es el arriendo de bienes inmuebles, el cual se da principalmente en verano, considerando de que es una cantidad indeterminadamente alta de situaciones, por lo que el Servicio no puede asistir caso a caso dada esta complejidad.

El SII le entrega mayor énfasis a la fiscalización del cumplimiento con respecto al IVA, dado a que este significa un porcentaje de ingreso considerable para el país, correspondiendo a casi un $50 \%$ de la recaudación total del país. Por otro lado, el Impuesto a la Renta posee solo un $40 \%$ de la recaudación en promedio, siendo el segundo más importante. Lo anteriormente señalado, explica que la tasa de evasión con respecto al IVA haya disminuido en los últimos años, esto por el énfasis en los planes implementados por el SIl para hacer frente a la evasión. Desde un punto de vista general, esto no responde a las cifras históricas con respecto a la evasión, dado a que la tasa de evasión de la Renta es mayor a la del IVA, y en relación a la evasión con respecto a los formularios de ambos tipos de impuestos, el asociado a la Renta es levemente mayor al del IVA, por lo que el enfoque se estaría dando con respecto a la ganancia que genera el impuesto, y no al incumplimiento con 
respecto a un impuesto y otro.

En relación a las medidas adoptadas por el SIl para hacer frente a las formas y figuras de evasión por parte de los contribuyentes, se observó que estas se realizan, en primer lugar, en base a acciones presenciales, como lo son las verificaciones en terreno y auditorías, las cuales han obtenido un mayor rendimiento con respecto a su objetivo, basado en obtener mayores ingresos en la recaudación tributaria del país. Por otro lado, las no presenciales, como las tecnologías de información, controles remotos de declaraciones juradas, de impuestos y otros, en donde actualmente el SIl cuenta con mayores recursos de apoyo con respecto a la modalidad, dado al enfoque que se le da a la fiscalización online, como lo son, por ejemplo, las notificaciones que entregan en su sitio web, a la hora de ingresar vía usuario y, también, mediante correos electrónicos que ejercen la función de notificación y respaldo. Lo anterior, se da con la idea de dar un servicio más factible, fiable, oportuno y rápido con respecto a la información que los contribuyentes entregan y a la fiscalización que el SIl les da a estos. La Reforma Tributaria del año 2014 también impone medidas relacionadas con la venta de bienes raíces, y con la idea de poner freno al mal uso de las compras con facturas que realizan las empresas en supermercados y comercios similares, medidas que se mantienen hasta el día de hoy, y que son constantemente actualizadas, con respecto a nuevos requerimientos.

La efectividad de las medidas se ve reflejada, en primer lugar, en la reforma tributaria impuesta por la presidenta Michelle Bachelet en su gobierno del año 2014, quien asegura un mejoramiento en la recaudación tributaria, esto por medio de una mejora en la distribución del ingreso, generar nuevos y más eficientes mecanismos con respecto al incentivo al ahorro, evitar la elución y evasión (mejorar efectividad y potenciar la fiscalización del SII). Gracias a esta ley, la recaudación de impuestos se vio favorecida para el año 2014 en un 17\%. Para el año 2015, el valor esperado con respecto a lo que se podía recaudar fue superado, esto en un $33,8 \%$. En segundo lugar, la aplicación del Plan de Gestión de Cumplimiento Tributario ha logrado que la tasa de evasión con respecto al IVA haya disminuido desde su aplicación, con respecto a años anteriores, lo que refleja la efectividad con respecto a las medidas impuestas en este. A su vez, el rendimiento estimado de los planes refleja que, gracias a las auditorías llevadas a cabo, se obtiene el mejor desempeño en cuanto a la nueva recaudación, seguido por los planes enfocados a la Renta, y finalmente el IVA. Para finalizar, se desprende que el mapa de riesgo muestra un alto cumplimiento con respecto a los contribuyentes.

\section{CONCLUSIONES}

Luego de efectuar los respectivos análisis y discusiones de los resultados obtenidos, es posible exponer las conclusiones que dan cumplimiento a los objetivos planteados al inicio de la investigación. 
La evasión tributaria nacional se puede dar, en primer lugar, por un desconocimiento de la normativa legal asociada a su cumplimiento por parte de los contribuyentes. El ejemplo más claro al respecto es el de la evasión al ejercer arrendamiento de bienes inmuebles, dado lo fácil que se podría dar esta actividad. Es por esto que se considera que el SII impuso medidas para enfrentarlo, como lo son las acciones correctivas. La otra cara de la moneda muestra la intensión explícita de evadir, como lo es al presentar facturas falsas 0 al no cumplir con los formularios de impuesto, contando con iniciación de actividades, recibiendo facturas de compra y emitiendo de venta.

Las medidas tomadas por el SIl para enfrentar las distintas formas y figuras de evasión en el país fueron recopiladas a partir del Plan de Gestión Tributario para cada período, comprendido entre 2014-2017, al cual se llegó gracias a las directrices entregadas por la Directora Regional del SII de la Región de Valparaíso, doña Teresa Conejeros Peña en carta entregada a modo de respuesta. Estas medidas se desglosan con respecto al IVA, Renta y enfoque mixto. Les medidas tomadas en esta investigación fueron las que se mantuvieron constantes en el tiempo, por lo tanto, se consideraron como las más importantes. Las medidas orientadas al IVA se enfocan con respecto al comercio informal, cambios de sujeto, control sobre las compras en supermercados y similares, exportadores y control sobre documentos tributarios. En relación a las medidas enfocadas a la Renta, se orientan al Plan Integral FUT, control de boletas de honorarios y facturas exentas, rentas originadas de instrumentos financieros, rentas de fuente extranjera y declaraciones juradas y formulario 22. El enfoque en ambos impuestos (mixto), se da en la medida orientada a los bienes raíces.

La efectividad de las técnicas fiscalizadoras del Servicio de Impuestos Internos se deduce a partir de las Cuentas Públicas publicadas el SIl para los períodos analizados. Esta se explica principalmente por la aplicación de la Reforma Tributaria impuesta por la presidenta Michelle Bachelet, quien asegura en un documento de declaración pública, un mejoramiento en la efectividad y la entrega de mayores recursos para la institución, para ejercer la fiscalización. Sumado a lo anterior, la creación de Planes de Gestión de Cumplimiento Tributario para cada año también ha llegado en forma de aporte, estableciendo la creación de medidas por medio de actividades preventivas y correctivas, que generan un balance positivo en la efectividad del cumplimiento tributario. Un indicador de rendimiento con respecto a la efectividad es la tasa de evasión, la cual, para el período comprendido, ha disminuido desde la puesta en marcha de lo anterior, logrando establecerse en un $20,8 \%$ en 2016 , siendo esta la más baja desde el año 2009 , esto para el caso del IVA. Otro indicador que se ha considerado para medir la efectividad, es el Rendimiento Estimado en relación al PGCT, el cual muestra un alto rendimiento en la contribución al ingreso tributario, en donde las auditorías logran el mayor rendimiento. Para el período comprendido entre los períodos 2013-2016, este rendimiento ha ido en aumento, lo cual refleja una mayor efectividad al pasar de los años. 


\section{REFERENCIAS BIBLIOGRÁFICAS}

- Barra P. y Jorrat M. (1999). Estimación de la evasión tributaria en Chile. Recuperado el 23 de abril de 2017, de http://www.sii.cl/aprenda_sobre_ impuestos/estudios/Antecede.htm

- Celedón, S. (2015). SIl fiscaliza a más de 1.700 contribuyentes por casos de evasión similares a Penta. Economía y Negocios Online. Recuperado julio 20, 2017 de http://www.economiaynegocios.cl/noticias/noticias. asp?id=137527

- Emol (2016). SIl detalla su plan de fiscalización de 2016 para bajar la evasión y elusión de impuestos. Recuperado el 23 de abril de 2017 de http://www.emol.com/noticias/Economia/2016/05/12/802506/ SII-detalla-su-plan-de-fiscalizacion-de-2016-para-bajar-la-evasion-yelusion-de-impuestos.html

- Hernández, H. (2008). Los cinco delitos tributarios que más complican al SII. Economía y Negocios Online. Recuperado julio 18, 2017 de http:// www.economiaynegocios.cl/noticias/noticias. asp?id $=45328$

- La Tercera (2014). Chile lidera en recaudación de impuestos a la renta en la región. Recuperado agosto 6, 2017 de http://www.latercera.com/noticia/ chile-lidera-en-recaudacion-de-impuestos-a-la-renta-en-la-region/

- Mora, D. y Mora, H. (2007). Causas y Efectos del Delito Tributario por Facturas Falsas en los Contribuyentes. Memoria para Optar a título de Contador Auditor. Departamento de Auditoría y Administración. Facultad de Ciencias Empresariales. Universidad del Bío-Bío. Recuperado julio 25, 2017 de http://cybertesis.ubiobio.cl/tesis/2007/mora_d/doc/mora_d.pdf

- Peña N. (2017). Arriendo de bienes amoblados: El foco de evasión tributaria que se dispara en verano. BioBio Chile Online. Recuperado el 19 de junio de 2017 de http://www.biobiochile.cl/noticias/nacional/ chile/2017/02/13/arriendo-de-bienes-amoblados-el-foco-de-evasiontributaria-que-se-dispara-en-verano.shtml

- SII (2005). Ley contra la Evasión Tributaria: Compromisos y Cumplimientos en el ámbito de la Administración [PDF]. Chile. Recuperado julio 03, 2017 de http://www.estimacionestributarias.com/archivos/evasion\%20en\%20 chile.pdf

- SIl (2012). Estimación de la evasión en el impuesto a la renta de las empresas serie 2003-2009 [PDF]. Recuperado julio 24, 2017. http://www. sii.cl/aprenda_sobre_impuestos/estudios/EstEvalRPCEmpresas03_09_ v20130326.pdf 
- SII (2014). Cuenta Pública 2013 [PDF]. Recuperado julio 25, 2017 de http://www.sii.cl/cuenta_publica/cta_2013.pdf

- SII (2015-A). Plan de Gestión de Cumplimiento Tributario 2015 [PDF]. Recuperado junio 27, 2017. http://www.sii.cl/sobre_el_sii/Plan_ Cumplimiento_tributario2015.pdf

- SII (2015-B). Cuenta Pública 2014 [PDF]. Recuperado julio 25, 2017 de http://www.sii.cl/cuenta_publica/cta_2014.pdf

- SII (2016-A). Serie de Ingresos Tributarios Anuales 2009-2016 [XLSX]. Recuperado julio 3, 2017. http://www.sii.cl/sobre_el_sii/serie_de_ ingresos_tributarios.html

- SII (2016-B). SII entrega detalles del Plan integral de Fiscalización para el 2016. Noticias SII. Recuperado junio 28, 2017 de http://www.sii.cl/ pagina/actualizada/noticias/2016/120516noti01srm.htm

- $\quad$ SII (2016-C). Serie de Evasión de IVA 2003-2015 [PDF]. Subdirección de Gestión Estratégica y Estudios Tributarios. Recuperado julio 24, 2017. http://www.sii.cl/estadisticas/evasion_iva_rt.pdf

- SII (2016-D). Cuenta Pública 2015 [PDF]. Recuperado julio 25, 2017 de http://www.sii.cl/cuenta_publica/CP2015.pdf

- $\quad$ SIl (2016-E). Ley de Impuesto al Valor Agregado. (1ºd.). Chile.

- SIl (2016-F). Plan de Gestión de Cumplimiento Tributario 2016 [PDF]. Recuperado junio 27, 2017. http://www.sii.cl/sobre_el_sii/plan_ cumplimiento_tributario2016.pdf

- $\quad$ SII (2017-A). Ley de la Renta. ( $1^{\circ}$ ed.). Chile.

- $\quad$ SII (2017-B). Cuenta Pública 2017 [PDF]. Recuperado julio 25, 2017. http://www.sii.cl/cuenta_publica/CP2017.pdf

- SII (2017-C). Plan de Gestión de Cumplimiento Tributario 2017 [PDF]. Recuperado junio 27, 2017. http://www.sii.cl/sobre_el_sii/plan_ cumplimiento_tributario2017.pdf

- Ugalde, R. y García, J. (Eds.). (2007). Elusión, planificación y evasión tributaria ( $2^{\circ}$ ed.). Santiago, Chile.

- Yáñez J. (2010). Evasión versus Elusión. Columna Diario Estrategia. Recuperado junio 21, 2017 de http://www.econ.uchile.cl/es/opinion/ evasi-n-versus-elusi-n-diario-estrategia 
Revista de Investigación Aplicada en Ciencias Empresariales 